\title{
Review Article \\ Short Tools to Assess Young Children's Dietary Intake: A Systematic Review Focusing on Application to Dietary Index Research
}

\author{
Lucinda K. Bell, ${ }^{1,2}$ Rebecca K. Golley, ${ }^{3}$ and Anthea M. Magarey ${ }^{1}$ \\ ${ }^{1}$ Department of Nutrition and Dietetics, Flinders University, Bedford Park, SA, 5042, Australia \\ ${ }^{2}$ Department of Nutrition and Dietetics, Flinders Clinical and Molecular Medicine, School of Medicine, Flinders Medical Centre, \\ Flinders University, Adelaide, SA, Australia \\ ${ }^{3}$ Public Health Group, Sansom Institute of Health Research, University of South Australia, 5000, Australia
}

Correspondence should be addressed to Lucinda K. Bell; lucy.bell@flinders.edu.au

Received 12 December 2012; Revised 19 April 2013; Accepted 18 July 2013

Academic Editor: Sarah McNaughton

Copyright (C) 2013 Lucinda K. Bell et al. This is an open access article distributed under the Creative Commons Attribution License, which permits unrestricted use, distribution, and reproduction in any medium, provided the original work is properly cited.

\begin{abstract}
Dietary indices evaluate diet quality, usually based on current dietary guidelines. Indices can therefore contribute to our understanding of early-life obesity-risk dietary behaviours. Yet indices are commonly applied to dietary data collected by onerous methods (e.g., recalls or records). Short dietary assessment instruments are an attractive alternative to collect data from which to derive an index score. A systematic review of studies published before April 2013 was conducted to identify short ( $\leq 50$ items) tools that measure whole-of-diet intake of young children (birth-five years) and are applicable to dietary indices, in particular screening obesogenic dietary behaviours. The search identified 3686 papers of which 16, reporting on 15 tools $(n=7$, infants and toddlers birth-24 months; $n=8$, preschoolers 2-5 years), met the inclusion criteria. Most tools were food frequency questionnaires $(n=14)$, with one innovative dietary questionnaire identified. Seven were tested for validity or reliability, and one was tested for both. Six tools ( $n=2$, infants and toddlers; $n=4$, preschoolers) are applicable for use with current dietary indices, five of which screen obesogenic dietary behaviours. Given the limited number of brief, valid and reliable dietary assessment tools for young children to which an index can be applied, future short tool development is warranted, particularly for screening obesogenic dietary behaviours.
\end{abstract}

\section{Introduction}

Individuals do not consume single nutrients, foods, or food groups, but rather combinations of foods [1]. Therefore in nutrition research it is appealing to capture the mix of foods and/or nutrients likely to influence health [2]. Dietary indices, for example evaluate diet quality by assessing dietary intake against predetermined criteria, usually reflecting current dietary guidelines [3].

Childhood overweight and obesity is a global health problem with 40 million children under the age of five classified as overweight [4]. Given the consequences of obesity and the persistence of obesity from childhood into adulthood [5], it is of major importance to address overweight early in life. As recommendations for overweight prevention and treatment are consistent with food-based dietary guidelines $[6,7]$, dietary indices offer a way of understanding the contribution of early life food intake to obesity risk.

Evaluation of diet against food-based dietary guidelines using an index [8] still requires accurate assessment of dietary intake at the food or food group level. In children under five, indices have commonly been applied to dietary data collected by 24-hour recalls, diet diaries, or weighed food records [9]. Yet, these methods are associated with high respondent burden and are cost- and time-intensive in terms of administration and analysis [10]. The use of these dietary assessment methods is a challenge in large epidemiological studies. Additionally, while energy and nutrient intakes can easily be derived from these detailed methods, it is often difficult to extract food intake data in a way that allows meaningful comparison with food-based dietary guidelines [8]. 


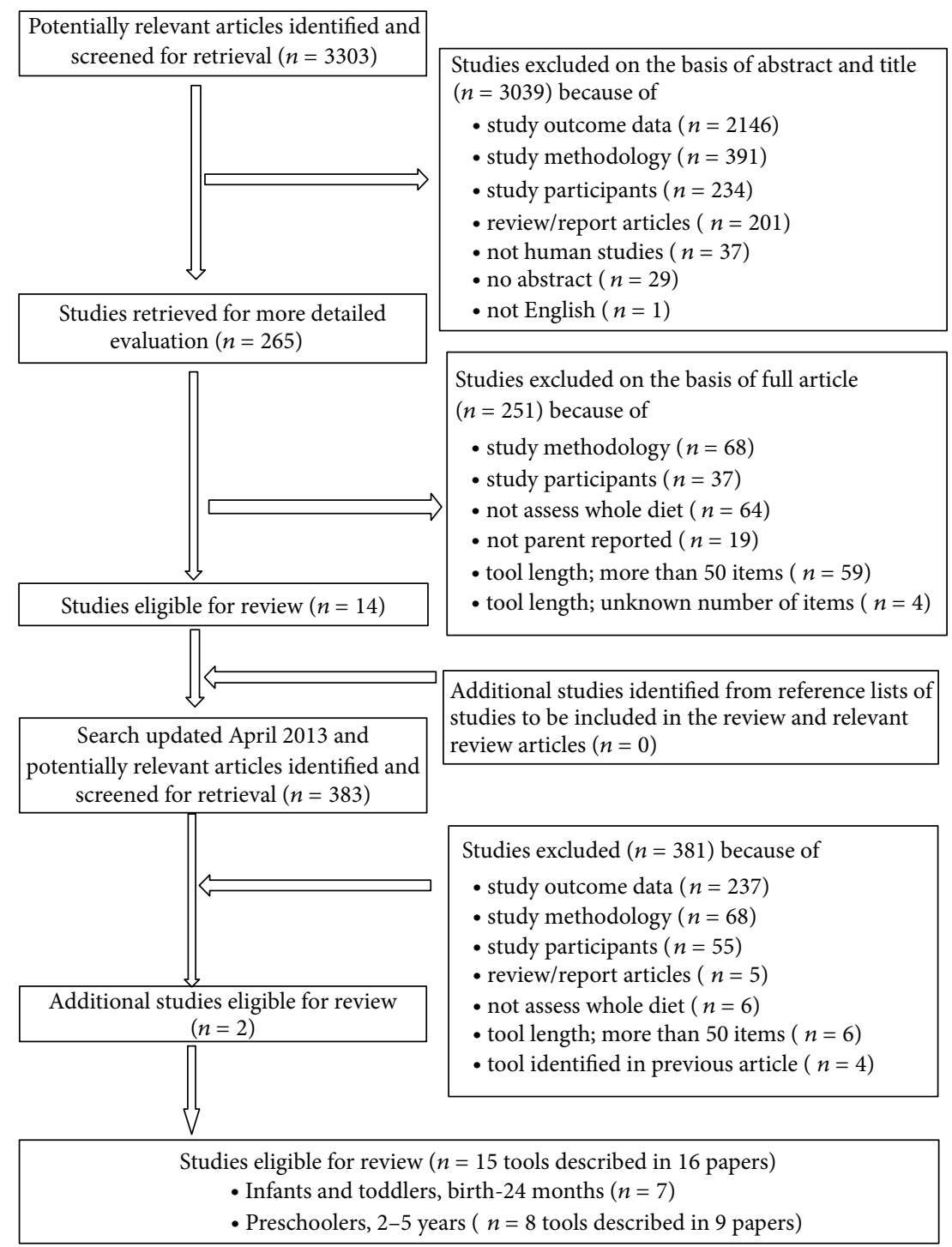

Figure 1: Quorom statement flow diagram. Studies assessing whole-of-diet intake of infants and toddlers and pre-schoolers using a short assessment tool.

Short, simple dietary assessment instruments are an attractive alternative to collect data from which to derive a diet quality score, as they are associated with reduced participant burden, data handling and processing, and costs. They are consequently suitable for survey or epidemiological research [11]. Further, as they supply information quickly [11], they are useful in clinical settings for the rapid assessment of individuals' food intake against food-based dietary guidelines. In view of the high worldwide childhood obesity rates, simple tools that assess early life obesogenic dietary habits are crucial. Given their advantages, short tools that enable evaluation of young children's dietary intake against foodbased dietary guidelines using a dietary index are required.

Thus, this review aimed to (1) examine short tools, including their reliability and validity, that measure diet of children birth-five years, (2) identify the short tools that could be used in dietary index research, including screening of obesogenic dietary behaviours.

\section{Methods}

2.1. Search and Selection Strategy. A six-stage systematic search was conducted to identify existing short tools that measure whole diet in young children. The search strategy and article selection are summarised in Figure 1. In stage one, MEDLINE via PubMed, Web of Science, and SCOPUS were searched for relevant articles published prior to June 2011. The search terms were developed and combined under the following headings: (1) child (birth-5 years), for example infant, toddler, preschooler, and child; (2) diet, for example food, nutrition, dietary intake, dietary pattern, eating pattern, food intake; (3) assessment tool, for example tool, dietary assessment, evaluate, questionnaire, checklist, validity, and reproducibility. Search term lists were comprehensive with small adaptations made for individual databases searched (see Supplementary information). Stage two involved elimination of irrelevant articles in Endnote using specific term 
searches through "title" and "keywords" (all terms presented in the Supplementary Information in Supplementary Material available online at http://dx.doi.org/10.1155/2013/709626). Subsequently, the title and abstract of the remaining 3303 articles were screened against the review inclusion and exclusion criteria, outlined below (stage three). If it was unclear whether an article should be included from the title and abstract, the full article was retrieved and screened (stage four). In stage five, reference lists of all included articles and relevant reviews were searched for additional studies. Lastly, searches were rerun in April 2013 to identify articles published after June 2011 (stage six). All resulting articles were screened according to stages two to five. Overall, all articles were assessed for eligibility independently by the primary author but in consultation with all coauthors.

2.2. Inclusion and Exclusion Criteria. The included studies were determined using the following criteria.

(1) Types of outcome measures: studies with whole-of diet intake data were included. Those assessing individual foods, food groups, nutrients or behaviours, and/or household, family, or group consumption were excluded.

(2) Types of dietary assessment methods: studies assessing dietary intake using a short dietary assessment tool were included. For example food frequency questionnaires, checklists, and other dietary questionnaires classified as 50 food intake questions or less. This criterion was set by the authors in an attempt to capture tools that were five pages or less and/or could be completed within 30 minutes. Articles were excluded if dietary assessment tools such as 24hour recalls, diet histories or food records were used to measure food intake, as they are considered standardised methods that are limited by complex researcher-based administration [12]. If the number of questionnaire items was not reported, or if the tool had been captured in a previously identified paper, articles were excluded.

(3) Types of participants: studies assessing dietary intake of healthy children aged birth to five years, reported by a parent or primary caregiver without assistance from the child, were included. Studies not applicable to the general population (e.g., preterm infants or children with disabilities, health conditions, or behavioural/learning difficulties) were excluded.

(4) Other: studies were limited to the English language, humans and those with an abstract. Review studies, reports, conference papers, and similar documents were excluded.

2.3. Data Extraction and Analysis. Data, including sample characteristics, questionnaire details, and reliability and validity were extracted into standardized tables by the principal author and checked for completion and accuracy by all coauthors. Data synthesis comprised grouping studies by age group and comparing in terms of dietary assessment characteristics; reliability (i.e., tool reproducibility or repeatability using a test-retest procedure [13]); validity (i.e., the ability to accurately measure food consumption data that represents the true intake of the individual [14], determined by comparison with an already validated method); and usefulness for current dietary index applications and screening obesogenic dietary behaviours. Applicability of tools to dietary indices was determined by comparing tool characteristics with characteristics of available indices for children aged up to five years, based on those identified in a recent review [9]. Tools were defined as applicable to dietary indices if all index components could be assessed both easily and accurately. Indices covering the five "core" food groups (i.e., foods recommended to be consumed every day including fruits; vegetables; cereals (e.g., bread, rice, and pasta, noodles); meat and alternatives (e.g., fish, eggs, and nuts); dairy), are highlighted. Indices suitable for screening obesogenic dietary behaviours were defined by the assessment of foods not included in the "core" food groups, described as "noncore" (energy-dense, low nutrient) foods and recommended to be consumed in minimal amounts $[6,15]$.

\section{Results}

3.1. General Description of Included Studies. Sixteen studies met the review inclusion criteria (Figure 1). The most common reason for exclusion was the type of outcome data $(n=2383)$, followed by study assessment methodology $(n=$ $526)$ and study participants $(n=322)$. The final 16 papers reported on 15 tools developed to assess dietary intake in early childhood (birth-5 years); seven evaluate infant and toddler dietary intake [16-22] eight evaluate preschoolers dietary intake [23-31] (Table 1). Studies included a range of population groups from predominately European $[16,17,19-$ $21,24-28]$ and other western countries [18, 23, 29-31] and were largely published from 2006 onwards [16, 18, 19, 23-31], with no retrieved papers published prior to 2000. The number of participants varied from 44 [25] to 27763 [17], with three studies presenting data from large, prospective birth cohorts UK Southampton Women's Study (SWS) [19], UK Avon Longitudinal Study of Parents and Children (ALSPAC) [16], and the Norwegian Mother and Child Cohort Study (MoBa) [17].

3.2. Dietary Assessment Methods and Testing. Most $(n=14$ of 15) tools used a food frequency questionnaire (FFQs) format $[16-28,30,31]$, with one innovative tool, the NutriSTEP nutrition screening tool for preschoolers, identified [29]. The majority of tools were self-administered [16-18, 20, 21, 23$29,31]$ and nonquantitative [16-18, 22-25, 29, 31]. The average tool length was 33 items (range 6-47), with 5 tools comprising less than 25 items $[18,20,21,23,29]$. Reference periods for recalling foods varied from the past week $[18,19,22]$ to past year $[27,28]$. Fourteen of the 16 studies reviewed reported food or food group intake as a tool outcome measure [16$18,20-27,29-31]$, whilst two reported energy and nutrient intakes only $[19,28]$. Overall, testing was undertaken on approximately half of identified tools $(n=7 / 15$, described in 8 papers) (Table 2). A range of tests to assess reliability and 


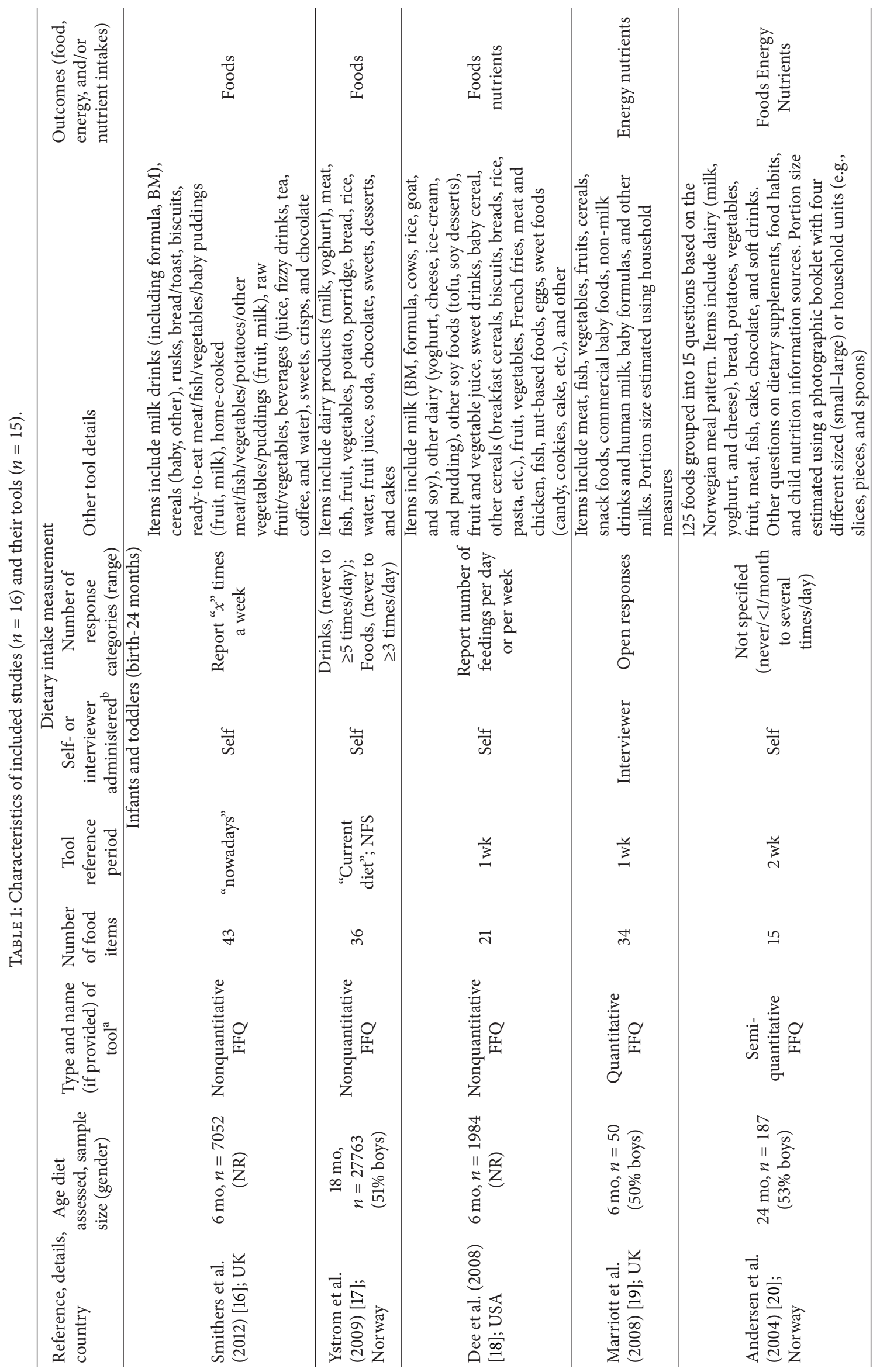




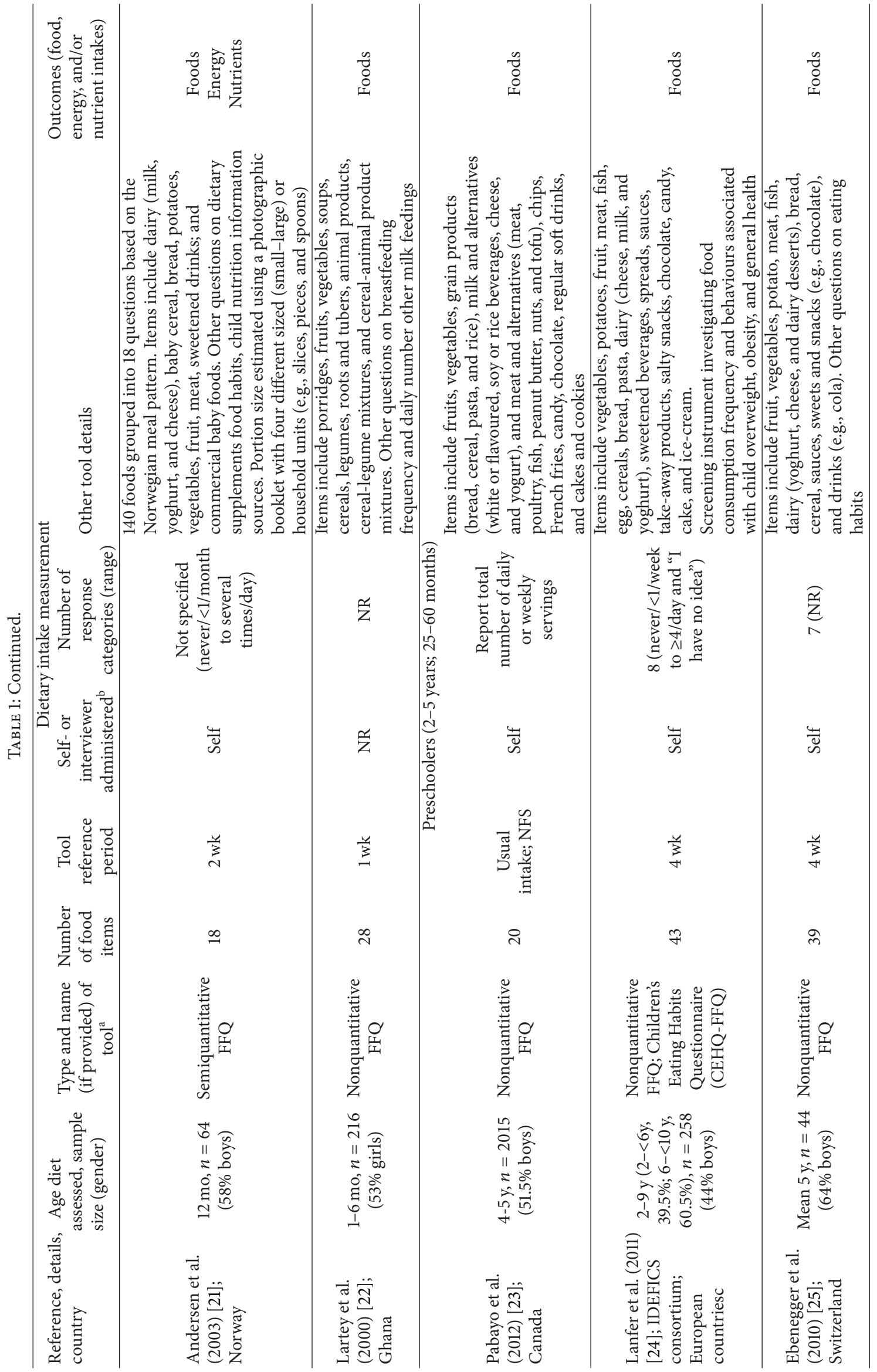




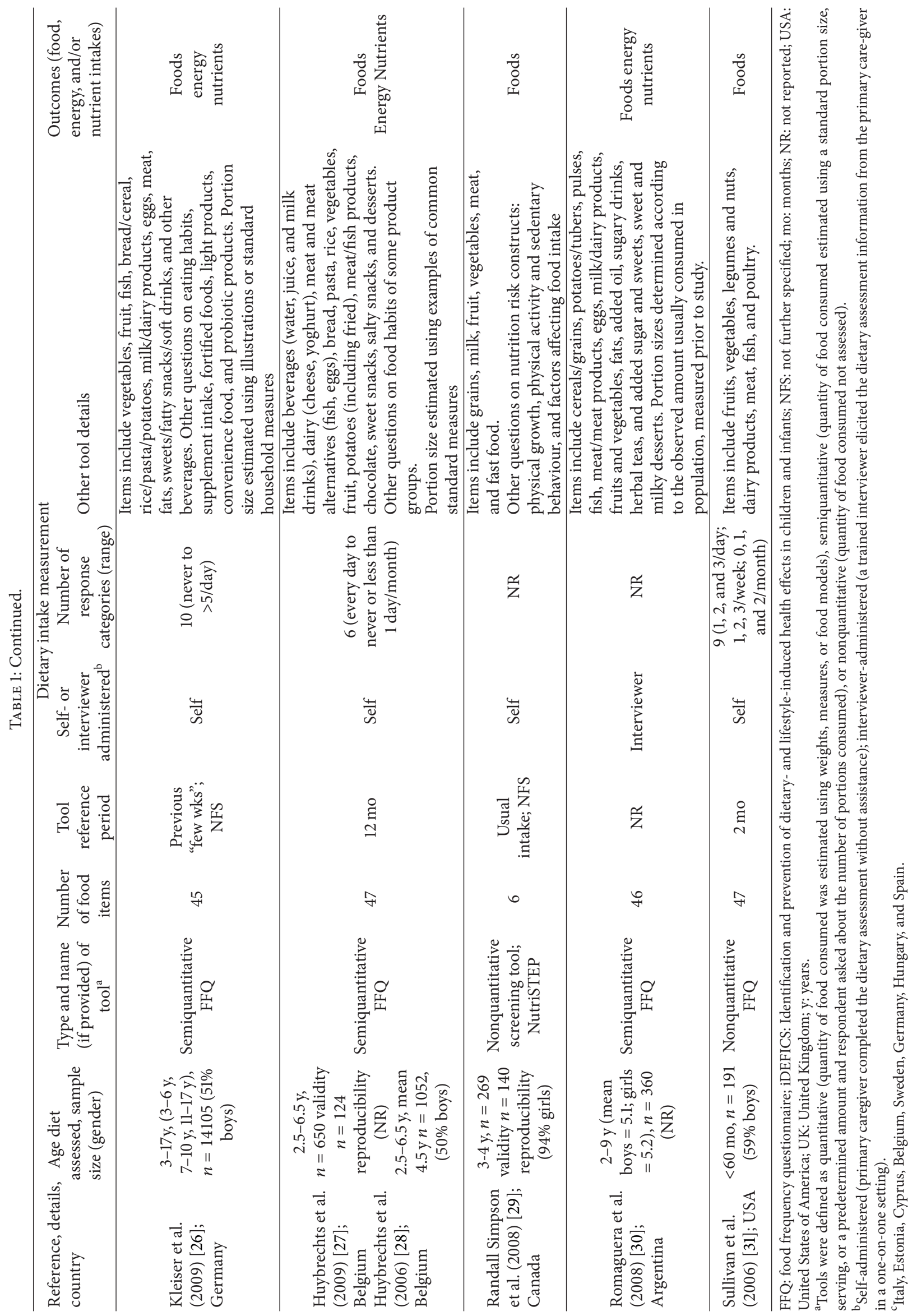


TABLE 2: Summary of availability of validity and reproducibility data for each study according to energy and/or nutrient intake and food intake.

\begin{tabular}{|c|c|c|c|c|}
\hline \multirow{2}{*}{ Reference details } & \multicolumn{2}{|l|}{ Validity } & \multicolumn{2}{|l|}{ Reliability } \\
\hline & Energy and/or nutrients & Foods & Energy and/or nutrients & Foods \\
\hline \multicolumn{5}{|l|}{ Infants and toddlers (birth-24 months) } \\
\hline Smithers et al. (2012) [16] & - & - & - & - \\
\hline Ystrom et al. (2009) [17] & - & - & - & - \\
\hline Dee et al. (2008) [18] & - & - & - & - \\
\hline Marriott et al. (2008) [19] & $\sqrt{ }$ & - & - & - \\
\hline Andersen et al. (2004) [20] & $\sqrt{ }$ & $\sqrt{ }$ & - & - \\
\hline Andersen et al. (2003) [21] & $\sqrt{ }$ & $\sqrt{ }$ & - & - \\
\hline Lartey et al. (2000) [22] & - & - & - & - \\
\hline \multicolumn{5}{|l|}{ Preschoolers ( $2-5$ years) } \\
\hline Pabayo et al. (2012) [23] & - & - & - & - \\
\hline Lanfer et al. (2011) [24] & - & - & - & $\sqrt{ }$ \\
\hline Ebenegger et al. (2010) [25] & - & - & - & $\sqrt{ }$ \\
\hline Kleiser et al. (2009) [26] & - & - & - & - \\
\hline Huybrechts et al. (2009) [27] & - & $\sqrt{ }$ & - & $\sqrt{ }$ \\
\hline Huybrechts et al. (2006) [28] & $\sqrt{ }$ & - & $\sqrt{ }$ & - \\
\hline Randall Simpson et al. (2008) [29] & - & - & - & $\sqrt{ }$ \\
\hline Romaguera et al. (2008) [30] & - & - & - & - \\
\hline Sullivan et al. (2006) [31] & - & - & - & - \\
\hline
\end{tabular}

validity were reported. Test definitions and review assessment criteria are presented in the Supplementary Table. Validity (Table 3 ) and/or reliability (Table 4 ) were most commonly tested using correlations, although agreement statistics were also used.

3.2.1. Infants and Toddlers (Birth-24 Months). All seven [1622] tools assessing infant and toddler dietary intakes were FFQs, ranging in length from 15 [20] to 43 [16] items. Three tools were evaluated for validity [19-21] (Table 4) whilst none were evaluated for reliability.

Validity testing revealed that the FFQs overestimated energy and nutrient intakes compared with the selected reference standard (all weighed dietary records, WDR) [19-21]. Correlations for energy and nutrients were low to moderate and slightly higher when energy adjusted [20, 21]. Bland Altman plots for nutrient intakes showed mostly positive mean differences [19], systematic increases in difference with increasing intake for most nutrients $[20,21]$ and large limits of agreement $[20,21]$. Little gross misclassification (3\% [21], $5 \%$ [20]), defined as classification of intake by the tool in the opposite quartile or tertile of intake, was reported with over one-third of subjects (38\% [21], 36\% [20]) classified into the same category of nutrient intake. At the food level, FFQ's generally revealed higher median intakes for several food items (11/17 [21] and 7/15 foods [20]) than the WDR $[20,21]$. Correlations for most foods were low or moderate with low $(r=0.48$ [20]) and moderate $(r=0.62$ [21]) overall median correlations. Importantly, no studies used agreement statistics at the food level.

3.2.2. Preschool Children (2-5 Years). Of the eight tools evaluating pre-schoolers' dietary intakes, described in nine papers [23-31], seven were FFQ's [23-28, 30, 31] but length varied widely (six [29] to 47 [27, 28, 31] items). Overall, three tools were assessed for reliability only $[24,25,29]$ and one for reliability and validity of food [27] and nutrient [28] intake (Tables 3 and 4).

To assess test-retest reliability [24, 25, 27-29] the period between administrations varied, ranging from two to four weeks [29] to an average of four months (range 0-364 days) [24]. No tool was assessed for reliability of energy intake and only one for nutrients [28]. The latter revealed that for average daily calcium intakes readministrations were not significantly different $(P=0.26)$, were highly correlated $(r=0.80)$ with moderate agreement $(k=0.60)$ and that nearly all subjects were classified into the same or adjacent quartile of intake (93\%) [28]. The reproducibility of food intake was assessed for four tools [24, 25, 27, 29] and showed no statistically significant differences for most foods (38/43 [24], 13/13 foods [27]). Mean spearman's correlations were moderate $(r=0.59$ [24], $r=0.62$ [25], and $r=0.64$ [27]) with good intraclass correlation coefficients (ICC's) reported for many food items ( $n=28 / 39$ [25]; $n=13 / 13$ [27]) and moderate overall mean ICC's $(r=0.59[25,27])$. Two studies showed moderate overall agreement for food items $(k=0.48$ [24], $k=0.55$ [29]).

Only one tool was assessed for validity, reported in two studies [27, 28]. This tool significantly underestimated calcium intake measured by an estimated dietary record (EDR), yet methods were moderately correlated $(r=0.52$, adjusted $r=0.59$ ) [28]. Sensitivity and specificity of calcium intake was $62 \%$ and $77 \%$, respectively, [28] and nearly half (42\%) of subjects were correctly classified [28]. Agreement statistics showed fair agreement $(k=0.38)$ and large differences for higher average nutrient intakes (Bland-Altman plot) [28]. For 


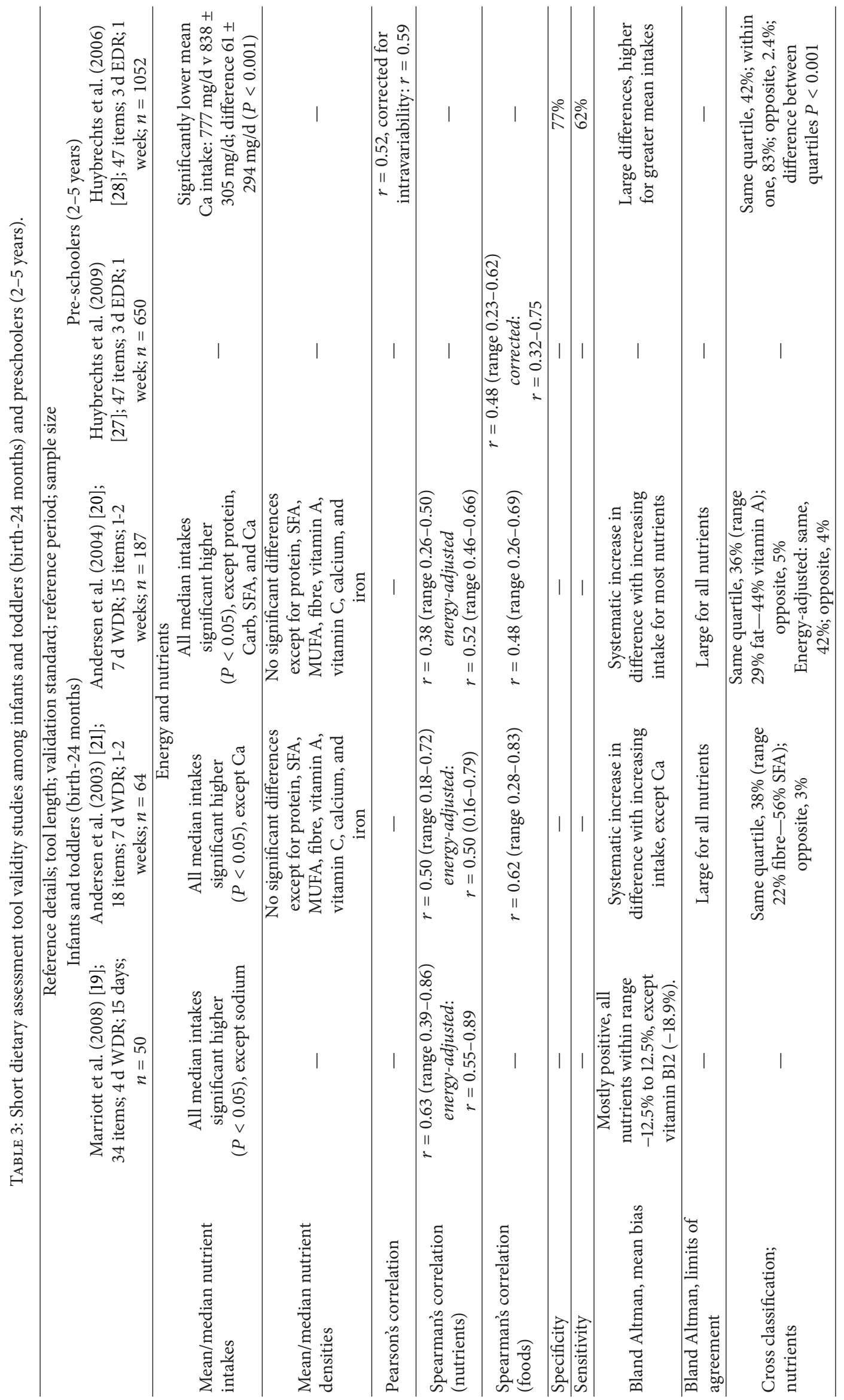




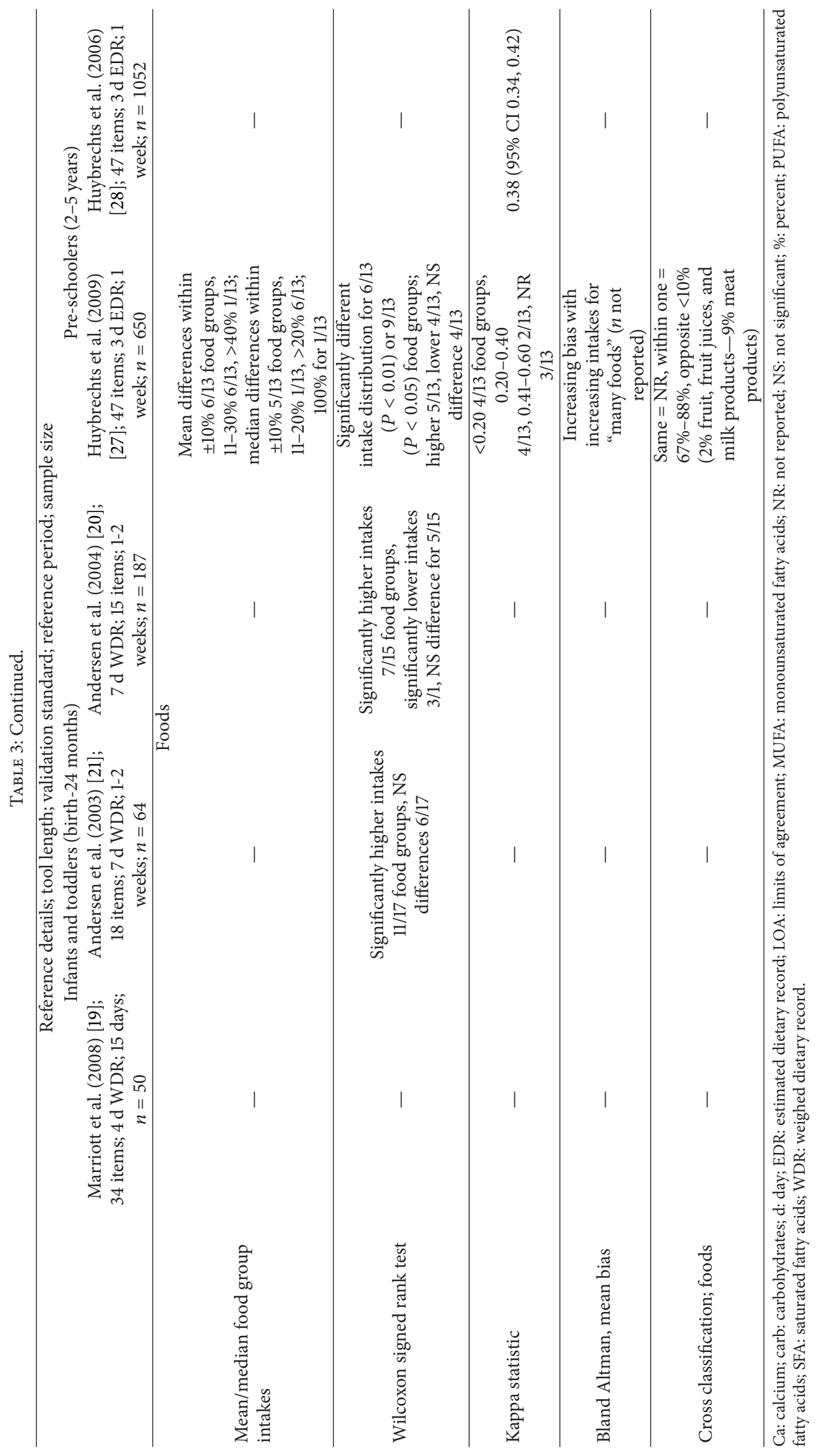




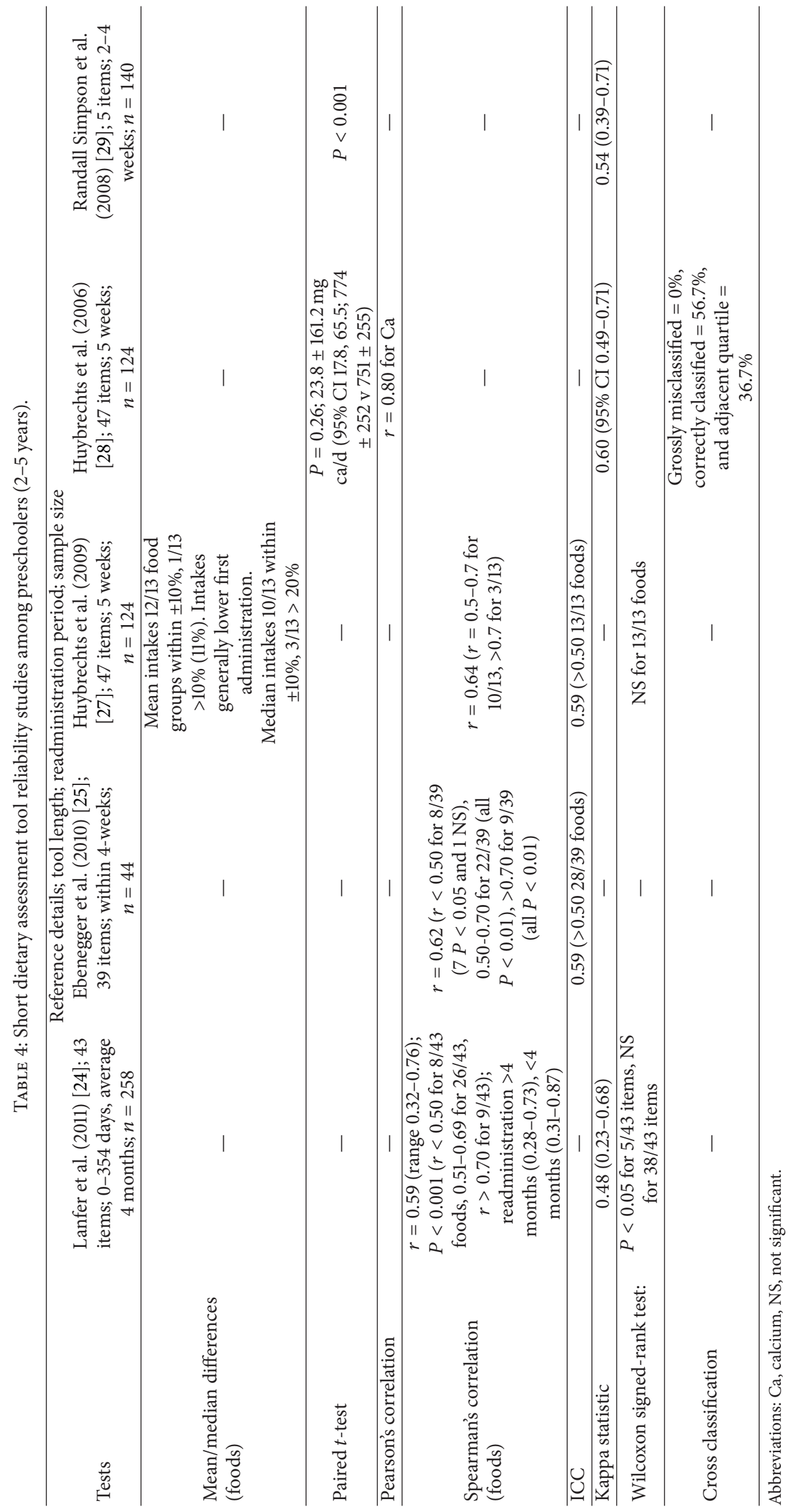


food intake, mean differences were predominately less than $30 \%$ (12/13 foods) [27], whilst the median correlation was low $(r=0.48$ [27]) and agreement mostly poor (4/13 foods) or fair (4/13 foods) [27]. Gross misclassification was less than $10 \%$ for all food groups whilst classification into the same or adjacent category ranged from $67 \%$ (meat products) to $88 \%$ (fruit juice) [27].

3.3. Dietary Index Applications. Dietary indices developed to characterise the diet quality of infants, toddlers or preschoolaged children are summarised in Table 5 [26, 31-48]. Overall, data from six tools $(n=2$, infants and toddlers [20, 21]; $n=4$, pre-schooler $[26,27,30,31])$ can be applied to five measures of diet quality reviewed [26, 31,39,42, 47], all developed for use in pre-schoolers (Table 5). Two have been tested for validity only $[20,21]$ and one for both validity and reliability [27]. Of these six short tools, two [26, 31], both for use in pre-schoolers, have previously been used in dietary index applications. The Healthy Nutrition Score for Kids and Youth (HuSKY) has been applied to the 54-item (45 food-item) semi-quantitative FFQ assessing intakes of three to six-year-old German children [26], whilst the 47-item nonquantitative FFQ has been used to assess dietary diversity in American children under five [31].

No other short tools were identified that provide dietary data to which a dietary index could be applied, often because the level of detail provided by the tool was too minimal for application of an index. This is particularly evident for those indices comprising food-group subcategories (e.g., "vitamin A-rich vegetables") $[33,36,38,43,44,48]$. Additionally, application of several tools to current indices would require detailed analysis to determine nutrient (e.g., total fat, cholesterol, and iron) intakes [32, 34, 40, 41, 43, 44, 46]. Lastly, portion size quantification is required for the majority of dietary indices reviewed $[26,32,34,36,38-44,46-48]$ and thus only quantitative or semiquantitative tools provide data to which these indices could be applied.

3.4. Screening Obesogenic Behaviours. Of the 15 tools reviewed, 13 assess the intake of "noncore" foods and/or beverages $(n=6$, infant and toddlers [16-21]; $n=7$ preschoolers [23-30]). Three of these were specifically designed to screen obesity related behaviours $[24,25,29]$ whilst five were identified (above) as being useful for application of a dietary index. Of the 19 indices reviewed [9], three $(n=1$, infants and toddlers [34]; $n=4$, pre-schoolers [26, 39]) included food items associated with poor diet quality, such as intake of high fat or sugary foods and/or beverages. Two of these indices can be used with the short tools identified in this review $[26,39]$.

\section{Discussion}

This review identified 16 papers reporting on 15 short dietary assessment tools that measure whole diet of children under five years ( $n=7$, infants and toddlers; $n=8$, pre-schoolers). Tool reliability and validity and applicability to dietary indices and for screening obesogenic dietary behaviours are highlighted. All but one tool was a FFQ, and approximately half $(n=7)$ of all tools were tested for either reliability or validity, and one tested for both. Six tools provide dietary intake data to which an index can be applied, five of which screen obesogenic dietary behaviours. Overall, testing of tool properties was limited and few tools are applicable to current dietary indices that screen obesogenic dietary behaviours of children from birth to five years of age.

Of the 15 tools identified in this review, only seven were tested for validity and/or reliability at the food or food group level. In general, there was a lack of reliability testing to accompany validity testing with only one of four tools assessed for validity also assessed for reliability. As validity requires reliability [49], the remaining three tools cannot be identified as valid. Moreover, there was a high reliance on correlations which assess association only and thus should not be used alone but alongside agreement measures such as kappa statistic and Bland-Altman analysis [50, 51]. Further, although the reference period covered by the validation standard should correspond to that of the questionnaire [52], 3- or 7-day food records were commonly used in the reviewed studies to assess the validity of FFQs covering two weeks [20, $21]$ or 12 months intake $[27,28]$. For reliability studies, if readministration periods are too close, subjects may remember their previous responses, or if too far apart, lower reliability may reflect true variation in diet [52], particularly in young children at an age when dietary habits are rapidly changing [53]. This is evident as an average re-administration period of 4 months yielded weaker agreement [24] than studies with shorter re-administration periods. Despite these limitations in tool testing, and in considering the realistic estimates of measurement error between two dietary assessment methods [54] in conjunction with unstable dietary habits of young children, the reliability and validity results presented here can be considered reasonable. Thus, several short dietary assessment tools can be judged as useful for characterising the diet of children under 5 .

Given the increasing interest in assessing diet quality using an index, resulting from an increased understanding of the complexity in which individuals consume foods [55], determining those short tools that are useful for dietary index applications is of interest. For the current indices available for children under five years of age, summarised in this review, diet quality is assessed based on intake of particular foods or food groups, nutrients, or a combination of both. Although most of the tools reviewed estimate whole-of-diet food intake making them potentially useful for food or food-group based index applications, few ( $n=6$ of 15) can be directly applied to current indices of diet quality [20,21, 26, 27, 30,31]. Further, these tools are limited by a lack of testing, with only one tested for reliability and validity $[27,28]$. Thus the accuracy of the other five tools in assessing dietary intake, and diet quality when applied to an index, is questionable. Therefore, testing of tool properties is recommended prior to dietary index applications.

Several factors explain why other short tools reviewed are not useful for dietary index applications. First, as mentioned, many indices assess diet quality based on nutrient intakes or a combination of nutrient and food intakes. Applying an index of this type to a questionnaire-type tool requires linkage with 


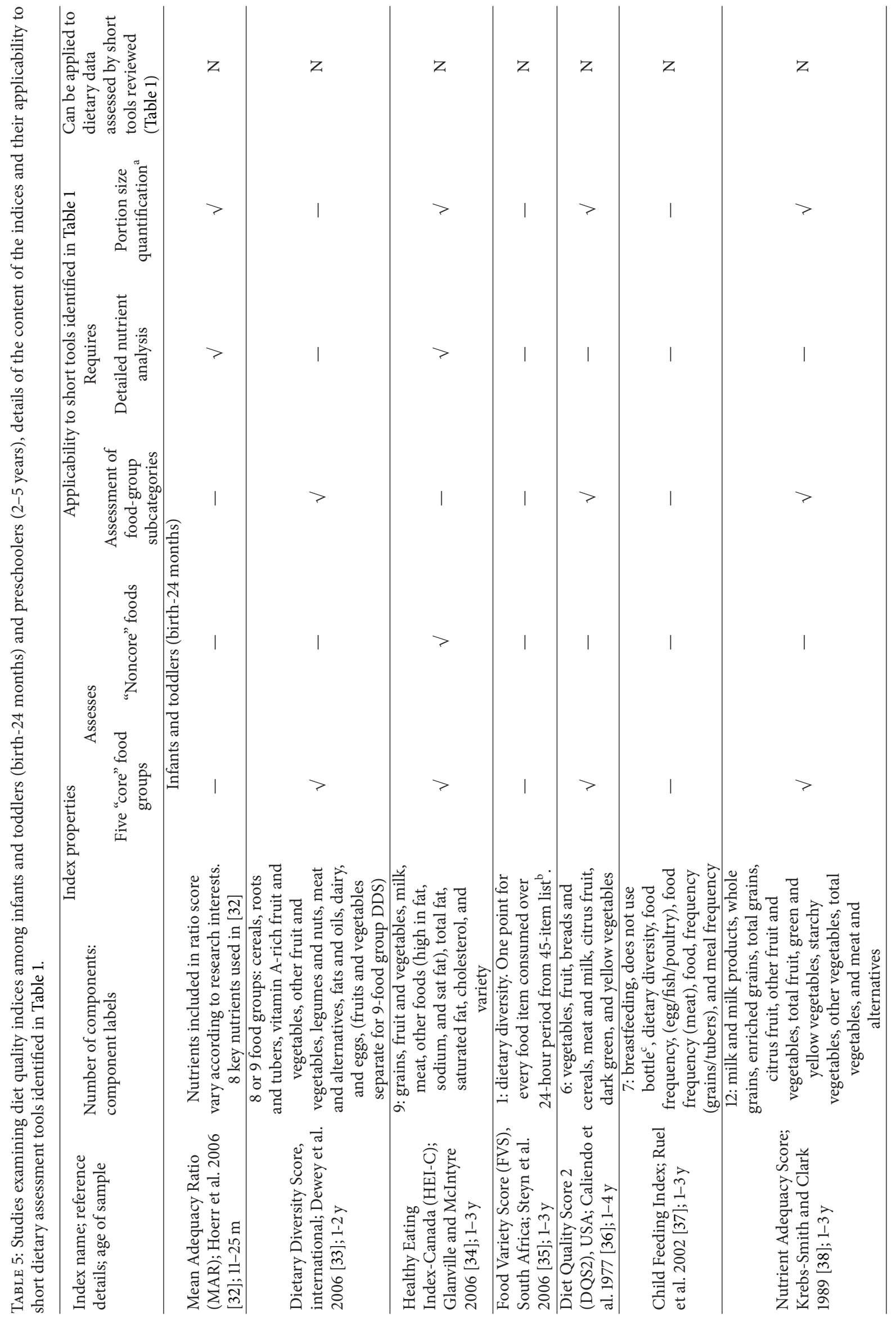




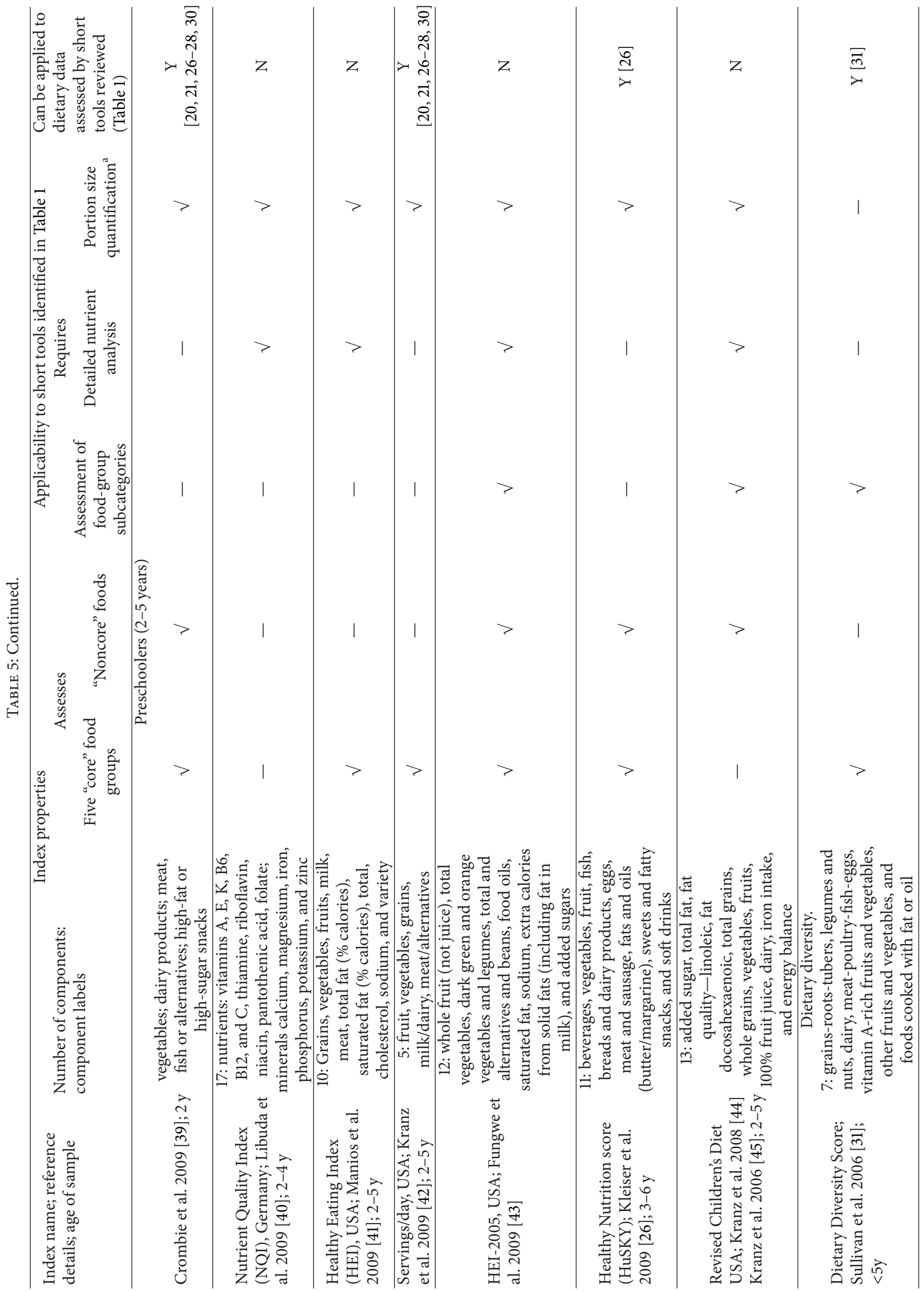




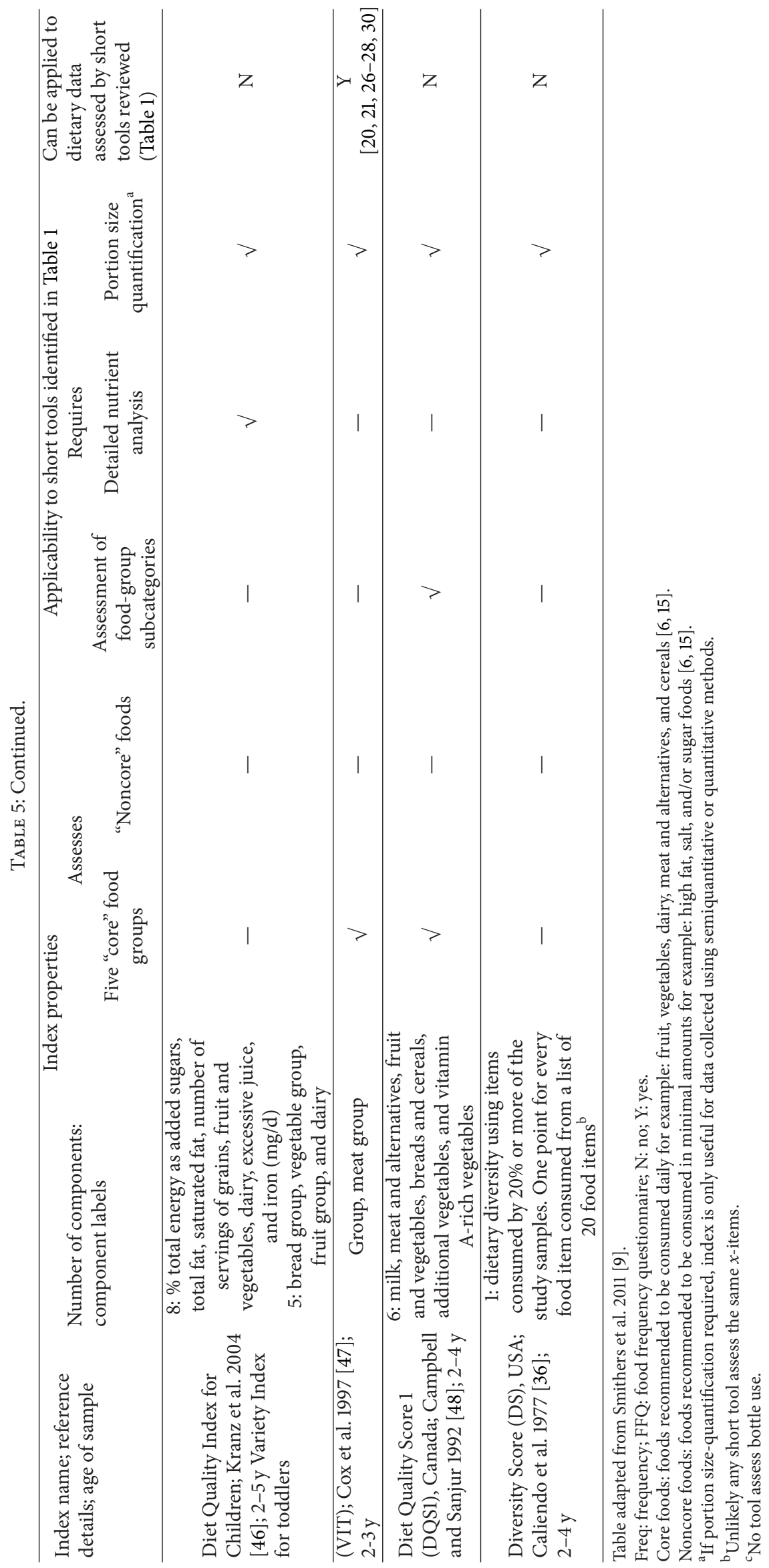


appropriate food composition data to derive nutrient intakes. Alternatively, questionnaire-type tools are most applicable to food-based indices. Further, several indices assess foodgroup subcategories, such as "vitamin A-rich vegetables" or "dark green vegetables," which are not measured by the short tools reviewed. Also limiting applicability is that portion size quantification is required to apply dietary data to several indices. Although these factors limit the applicability of short tools to current indices, several tools that capture food groups of interest are ideal for development of a suitable index. For example the 47-item FFQ by Huybrechts et al. [27] is suitable as it assesses "core" and "noncore" food intake and was the one tool tested for both reliability and validity of food intake. Development of a dietary index based on food intake assessed using this short tool would be appropriate. Alternatively, future research to develop suitable short dietary assessment tools that measure whole diet to which a current index can be applied is ideal.

Moreover, in view of the high rates of overweight and obesity among children under five worldwide [4], indices are potentially a useful tool to evaluate early life dietary behaviours that contribute to obesity risk. Yet few current indices for children less than five years assess obesogenic dietary behaviours, with many evaluating "core" food and/or nutrient intakes only. Thus, future indices based on "core" and "noncore" food intake are warranted. Additionally, considering that few short tools assess "noncore" intakes and are useful for application of a dietary intake there is a need for future development of short tools that are useful for both dietary index applications and screening obesogenic dietary behaviours in children under five, particularly in those less than two years of age.

Overall, this systematic review highlights the lack of high quality short dietary intake assessment tools for young children, particularly less than two years, to which a dietary index can be applied. Further, as the majority of those tools available for dietary index applications were developed and tested in European populations, restricting their generalisability outside the European context, there is a need for short dietary assessment tools developed for use in other populations of young children to which an index can be applied. Lastly, it is important to note that several rapid dietary assessment tools have been designed for use in young children, yet are not presented in this review as they focus on limited aspects of food intake, for example fruit and vegetables [56], beverages [57], and obesity-related food and beverages only [58], not total diet. Future rapid dietary assessment tools should be designed to comprehensively measure young children's whole-of-diet intake, including obesogenic dietary behaviours, and should be tested for reliability and validity of food intake.

\section{Conclusion}

A key finding of this review is that although several short dietary assessment tools were identified as useful for characterising whole diet of children birth-5 years, there is an overall lack of brief, valid and reliable dietary assessment tools available for use in this age group. This highlights a need for greater testing of existing short tools. A second key finding is that few short dietary assessment tools, particularly those developed for under 2's, are suitable for dietary index applications and for screening obesogenic dietary behaviours of young children. Due to the benefits of assessing diet quality using indices and of capturing dietary intake using less demanding, time-consuming and expensive dietary assessment methodologies, this review identifies opportunities for short tool development for use in children under five that are adequately reliable and valid for use, applicable to dietary indices, and that assess obesogenic dietary behaviours.

\section{Conflicts of Interests}

The authors declare no conflict of interests.

\section{Acknowledgments}

Rebecca K. Golley is supported by a National Heart Foundation Fellowship, and Lucinda K. Bell is supported by an Australian Postgraduate Award (APA).

\section{References}

[1] A. K. Kant, "Dietary patterns and health outcomes," Journal of the American Dietetic Association, vol. 104, no. 4, pp. 615-635, 2004.

[2] F. B. Hu, "Dietary pattern analysis: a new direction in nutritional epidemiology," Current Opinion in Lipidology, vol. 13, no. 1, pp. 3-9, 2002.

[3] P. K. Newby and K. L. Tucker, "Empirically derived eating patterns using factor or cluster analysis: a review," Nutrition Reviews, vol. 62, no. 5, pp. 177-203, 2004.

[4] WHO, "Obesity and overweight," World Health Organization (WHO), 2011, http://www.who.int/mediacentre/factsheets/fs311/ en/.

[5] A. M. Craigie, A. A. Lake, S. A. Kelly, A. J. Adamson, and J. C. Mathers, "Tracking of obesity-related behaviours from childhood to adulthood: a systematic review," Maturitas, vol. 70, no. 3, pp. 266-284, 2010.

[6] NHMRC, Dietary Guidelines for Children and Adolescents in Australia Incorporating the Infant Feeding Guidelines for Health Workers, National Health and Medical Research Council (NHMRC), Commonwealth of Australia, Canberra, Australia, 2003.

[7] NHMRC, Clinical Practice Guidelines for the Management of Overweight and Obesity in Children and Adolescents, National Health and Medical Research Council (NHMRC), Commonwealth of Australia, Canberra, Australia, 2003.

[8] A. Magarey, R. K. Golley, N. Spurrier, E. Goodwin, and F. Ong, "Reliability and validity of the children's dietary questionnaire; a new tool to measure children's dietary patterns," International Journal of Pediatric Obesity, vol. 4, no. 4, pp. 257-265, 2009.

[9] L. G. Smithers, R. K. Golley, L. Brazionis, and J. W. Lynch, "Characterizing whole diets of young children from developed countries and the association between diet and health: a systematic review," Nutrition Reviews, vol. 69 , no. 8, pp. 449467, 2011. 
[10] A. Magarey, J. Watson, R. K. Golley et al., "Assessing dietary intake in children and adolescents: considerations and recommendations for obesity research," International Journal of Pediatric Obesity, vol. 6, no. 1, pp. 2-11, 2011.

[11] V. Flood, K. Webb, and A. Rangan, "Recommendations for short questions to assess food consumption in children for the NSW health surveys," NSW Centre for Public Health Nutrition, 2005, http://www0.health.nsw.gov.au/pubs/2005/pdf/qa_food_consump.pdf.

[12] T. Burrows, R. K. Golley, A. Khambalia et al., "The quality of dietary intake methodology and reporting in child and adolescent obesity intervention trials: a systematic review," Obesity Reviews, vol. 13, no. 12, pp. 1125-1138, 2012.

[13] P. M. Gleason, J. Harris, P. M. Sheean, C. J. Boushey, and B. Bruemmer, "Publishing nutrition research: validity, reliability, and diagnostic test assessment in nutrition-related research," Journal of the American Dietetic Association, vol. 110, no. 3, pp. 409-419, 2010.

[14] J. Pallant, SPSS Survival Manual: A Step by Step Guide to Data Analysis Using SPSS, Allen \& Unwin, 4th edition, 2011.

[15] L. Kellet, A. Smith, and Y. Schmerlaib, Australian Guide to Healthy Eating, Department of Health and Family Services, Commonwealth of Australia, Canberra, Australia, 1998.

[16] L. G. Smithers, L. Brazionis, R. K. Golley et al., "Associations between dietary patterns at 6 and 15 months of age and sociodemographic factors," European Journal of Clinical Nutrition, vol. 66, no. 6, pp. 658-666, 2012.

[17] E. Ystrom, S. Niegel, and M. E. Vollrath, "The impact of maternal negative affectivity on dietary patterns of 18 -monthold children in the Norwegian mother and child cohort study," Maternal and Child Nutrition, vol. 5, no. 3, pp. 234-242, 2009.

[18] D. L. Dee, A. J. Sharma, M. E. Cogswell, L. M. Grummer-Strawn, S. B. Fein, and K. S. Scanlon, "Sources of supplemental iron among breastfed infants during the first year of life," Pediatrics, vol. 122, supplement 2, pp. S98-S104, 2008.

[19] L. D. Marriott, S. M. Robinson, J. Poole et al., "What do babies eat? Evaluation of a food frequency questionnaire to assess the diets of infants aged 6 months," Public Health Nutrition, vol. 11, no. 7, pp. 751-756, 2008.

[20] L. F. Andersen, B. Lande, K. Trygg, and G. Hay, "Validation of a semi-quantitative food-frequency questionnaire used among 2-year-old Norwegian children," Public Health Nutrition, vol. 7, no. 6, pp. 757-764, 2004.

[21] L. F. Andersen, B. Lande, G. H. Arsky, and K. Trygg, "Validation of a semi-quantitative food-frequency questionnaire used among 12-month-old Norwegian infants," European Journal of Clinical Nutrition, vol. 57, no. 8, pp. 881-888, 2003.

[22] A. Lartey, A. Manu, K. H. Brown, J. M. Peerson, and K. G. Dewey, "Predictors of growth from 1 to 18 months among breast-fed Ghanaian infants," European Journal of Clinical Nutrition, vol. 54, no. 1, pp. 41-49, 2000.

[23] R. Pabayo, J. C. Spence, L. Casey, and K. Storey, "Food consumption patterns in preschool children," Canadian Journal of Dietetic Practice and Research, vol. 73, no. 2, pp. 66-71, 2012.

[24] A. Lanfer, A. Hebestreit, W. Ahrens et al., "Reproducibility of food consumption frequencies derived from the children's eating habits questionnaire used in the IDEFICS study," International Journal of Obesity, vol. 35, supplement 1, pp. S61-S68, 2011.

[25] V. Ebenegger, P. Marques-Vidal, J. Barral, S. Kriemler, J. J. Puder, and A. Nydegger, "Eating habits of preschool children with high migrant status in Switzerland according to a new food frequency questionnaire," Nutrition Research, vol. 30, no. 2, pp. 104-109, 2010.

[26] C. Kleiser, G. B. M. Mensink, C. Scheidt-Nave, and B. M. Kurth, "HuSKY: a healthy nutrition score based on food intake of children and adolescents in Germany," The British Journal of Nutrition, vol. 102, no. 4, pp. 610-618, 2009.

[27] I. Huybrechts, G. de Backer, D. de Bacquer, L. Maes, and S. de Henauw, "Relative validity and reproducibility of a foodfrequency questionnaire for estimating food intakes among flemish preschoolers," International Journal of Environmental Research and Public Health, vol. 6, no. 1, pp. 382-399, 2009.

[28] I. Huybrechts, D. de Bacquer, C. Matthys, G. de Backer, and S. de Henauw, "Validity and reproducibility of a semi-quantitative food-frequency questionnaire for estimating calcium intake in Belgian preschool children," The British Journal of Nutrition, vol. 95, no. 4, pp. 802-816, 2006.

[29] J. A. Randall Simpson, H. H. Keller, L. A. Rysdale, and J. E. Beyers, "Nutrition screening tool for every preschooler (NutriSTEP): validation and test-retest reliability of a parent-administered questionnaire assessing nutrition risk of preschoolers," European Journal of Clinical Nutrition, vol. 62, no. 6, pp. 770-780, 2008.

[30] D. Romaguera, N. Samman, A. Rossi, C. Miranda, A. Pons, and J. A. Tur, "Dietary patterns of the Andean population of Puna and Quebrada of Humahuaca, Jujuy, Argentina," The British Journal of Nutrition, vol. 99, no. 2, pp. 390-397, 2008.

[31] J. Sullivan, M. Ndekha, D. Maker, C. Hotz, and M. J. Manary, "The quality of the diet in Malawian children with kwashiorkor and marasmus," Maternal and Child Nutrition, vol. 2, no. 2, pp. 114-122, 2006.

[32] S. L. Hoerr, M. A. Horodynski, S. Y. Lee, and M. Henry, "Predictors of nutritional adequacy in mother-toddler dyads from rural families with limited incomes," Journal of the American Dietetic Association, vol. 106, no. 11, pp. 1766-1773, 2006.

[33] K. G. Dewey, A. W. Onyango, and C. Garza, "Complementary feeding in the WHO multicentre growth reference study," Acta Paediatrica, vol. 95, no. 450, pp. 27-37, 2006.

[34] N. T. Glanville and L. McIntyre, "Diet quality of atlantic families headed by single mothers," Canadian Journal of Dietetic Practice and Research, vol. 67, no. 1, pp. 28-35, 2006.

[35] N. P. Steyn, J. H. Nel, G. Nantel, G. Kennedy, and D. Labadarios, "Food variety and dietary diversity scores in children: are they good indicators of dietary adequacy?" Public Health Nutrition, vol. 9, no. 5, pp. 644-650, 2006.

[36] M. A. Caliendo, D. Sanjur, J. Wright, and G. Cummings, "Nutritional status of preschool children," Journal of the American Dietetic Association, vol. 71, no. 1, pp. 20-26, 1977.

[37] M. T. Ruel and P. Menon, "Child feeding practices are associated with child nutritional status in Latin America: innovative uses of the demographic and health surveys," Journal of Nutrition, vol. 132, no. 6, pp. 1180-1187, 2002.

[38] S. M. Krebs-Smith and L. D. Clark, "Validation of a nutrient adequacy score for use with women and children," Journal of the American Dietetic Association, vol. 89, no. 6, pp. 775-783, 1989.

[39] I. K. Crombie, K. Kiezebrink, L. Irvine et al., "What maternal factors influence the diet of 2-year-old children living in deprived areas? A cross-sectional survey," Public Health Nutrition, vol. 12, no. 8, pp. 1254-1260, 2009.

[40] L. Libuda, U. Alexy, A. E. Buyken, W. Sichert-Hellert, P. Stehle, and M. Kersting, "Consumption of sugar-sweetened beverages 
and its association with nutrient intakes and diet quality in German children and adolescents," The British Journal of Nutrition, vol. 101, no. 10, pp. 1549-1557, 2009.

[41] Y. Manios, G. Kourlaba, K. Kondaki et al., "Diet quality of preschoolers in Greece based on the healthy eating index: the GENESIS study," Journal of the American Dietetic Association, vol. 109, no. 4, pp. 616-623, 2009.

[42] S. Kranz, D. C. Mitchell, H. Smiciklas-Wright, S. H. Huang, S. K. Kumanyika, and N. Stettler, "Consumption of recommended food groups among children from medically underserved communities," Journal of the American Dietetic Association, vol. 109, no. 4, pp. 702-707, 2009.

[43] T. Fungwe, P. M. Guenther, W. Y. Juan et al., "The quality of children's diets in 2003-2004 as measured by the healthy eating index-2005," Clinical Nutrition Insight, vol. 43, pp. 1-2, 2009.

[44] S. Kranz, J. L. Findeis, and S. S. Shrestha, "Use of the revised children's diet quality index to assess preschooler's diet quality, its sociodemographic predictors, and its association with body weight status," Jornal de Pediatria, vol. 84, no. 1, pp. 26-34, 2008.

[45] S. Kranz, T. Hartman, A. M. Siega-Riz, and A. H. Herring, "A diet quality index for American preschoolers based on current dietary ntake recommendations and an indicator of energy balance," Journal of American Dietetic Association, vol. 106, no. 10, pp. 1594-1604, 2006.

[46] S. Kranz, A. M. Siega-Riz, and A. H. Herring, "Changes in diet quality of American preschoolers between 1977 and 1998," The American Journal of Public Health, vol. 94, no. 9, pp. 1525-1530, 2004.

[47] D. R. Cox, J. D. Skinner, B. R. Carruth, J. Moran III, and K. S. Houck, "A food variety index for toddlers (VIT): development and application," Journal of the American Dietetic Association, vol. 97, no. 12, pp. 1382-1386, 1997.

[48] M. L. Campbell and D. Sanjur, "Single employed mothers and preschool-child nutrition: an ecological analysis," Journal of Nutrition Education and Behavior, vol. 24, no. 2, pp. 67-74, 1992.

[49] W. P. Vogt, Dictionary of Statistics \& Methodology: A Nontechnical Guide for the Social Sciences, Sage, Thousand Oaks, Calif, USA, 2nd edition, 1999.

[50] J. M. Bland and D. G. Altman, "Comparing methods of measurement: why plotting difference against standard method is misleading," The Lancet, vol. 346, no. 8982, pp. 1085-1087, 1995.

[51] J. M. Bland and D. G. Altman, "Measuring agreement in method comparison studies," Statistical Methods in Medical Research, vol. 8, no. 2, pp. 135-160, 1999.

[52] J. Cade, R. Thompson, V. Burley, and D. Warm, "Development, validation and utilisation of food-frequency questionnaires-a review," Public Health Nutrition, vol. 5, no. 4, pp. 567-587, 2002.

[53] L. A. Parrish, J. A. Marshall, N. F. Krebs, M. Rewers, and J. M. Norris, "Validation of a food frequency questionnaire in preschool children," Epidemiology, vol. 14, no. 2, pp. 213-217, 2003.

[54] B. M. Margetts and M. Nelson, Design Concepts in Nutritional Epidemiology, Oxford University Press, Oxford, UK, 1997.

[55] P. M. C. M. Waijers, E. J. M. Feskens, and M. C. Ocké, "A critical review of predefined diet quality scores," The British Journal of Nutrition, vol. 97, no. 2, pp. 219-231, 2007.

[56] C. Linneman, K. Hessler, S. Nanney, K. Steger-May, A. Huynh, and D. Haire-Joshu, "Parents are accurate reporters of their preschoolers' fruit and vegetable consumption under limited conditions," Journal of Nutrition Education and Behavior, vol. 36, no. 6, pp. 305-308, 2004.
[57] T. A. Marshall, J. M. E. Gilmore, B. Broffitt, S. M. Levy, and P. J. Stumbo, "Relative validation of a beverage frequency questionnaire in children ages 6 months through 5 years using 3-day food and beverage diaries," Journal of the American Dietetic Association, vol. 103, no. 6, pp. 714-720, 2003.

[58] C. A. Bennett, A. M. de Silva-Sanigorski, M. Nichols, A. C. Bell, and B. A. Swinburn, "Assessing the intake of obesity-related foods and beverages in young children: comparison of a simple population survey with $24 \mathrm{hr}$-recall," International Journal of Behavioral Nutrition and Physical Activity, vol. 6, article 71, 2009. 


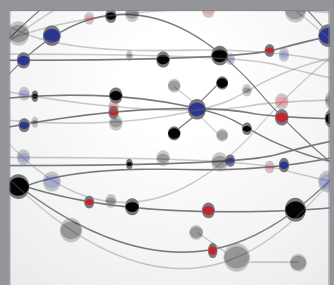

The Scientific World Journal
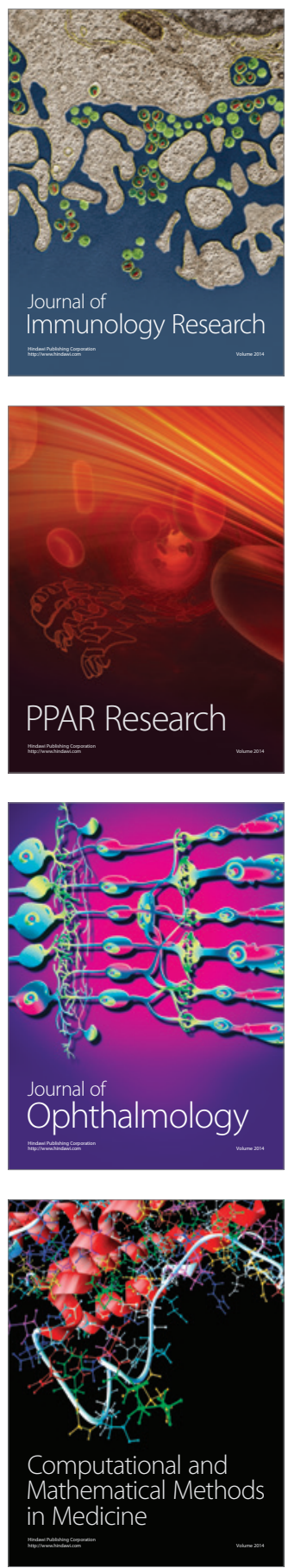

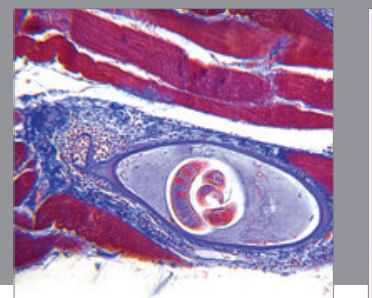

Gastroenterology

Research and Practice
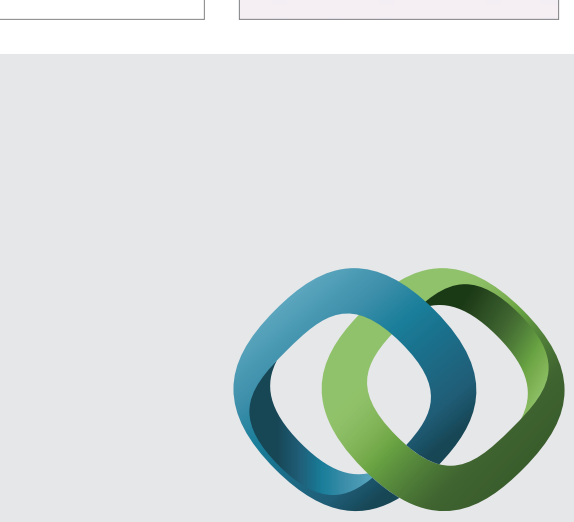

\section{Hindawi}

Submit your manuscripts at

http://www.hindawi.com
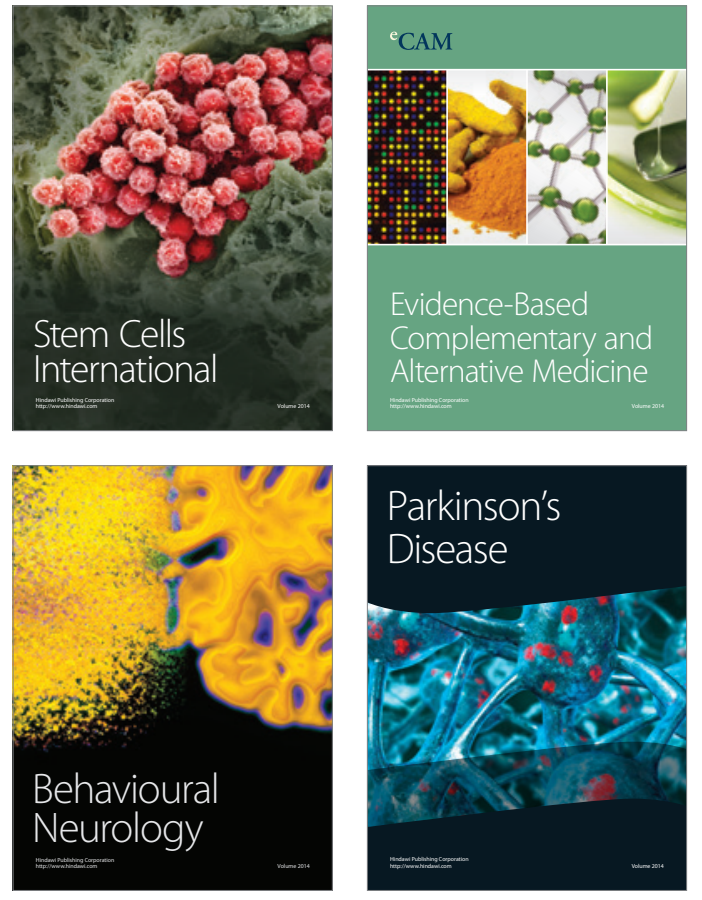
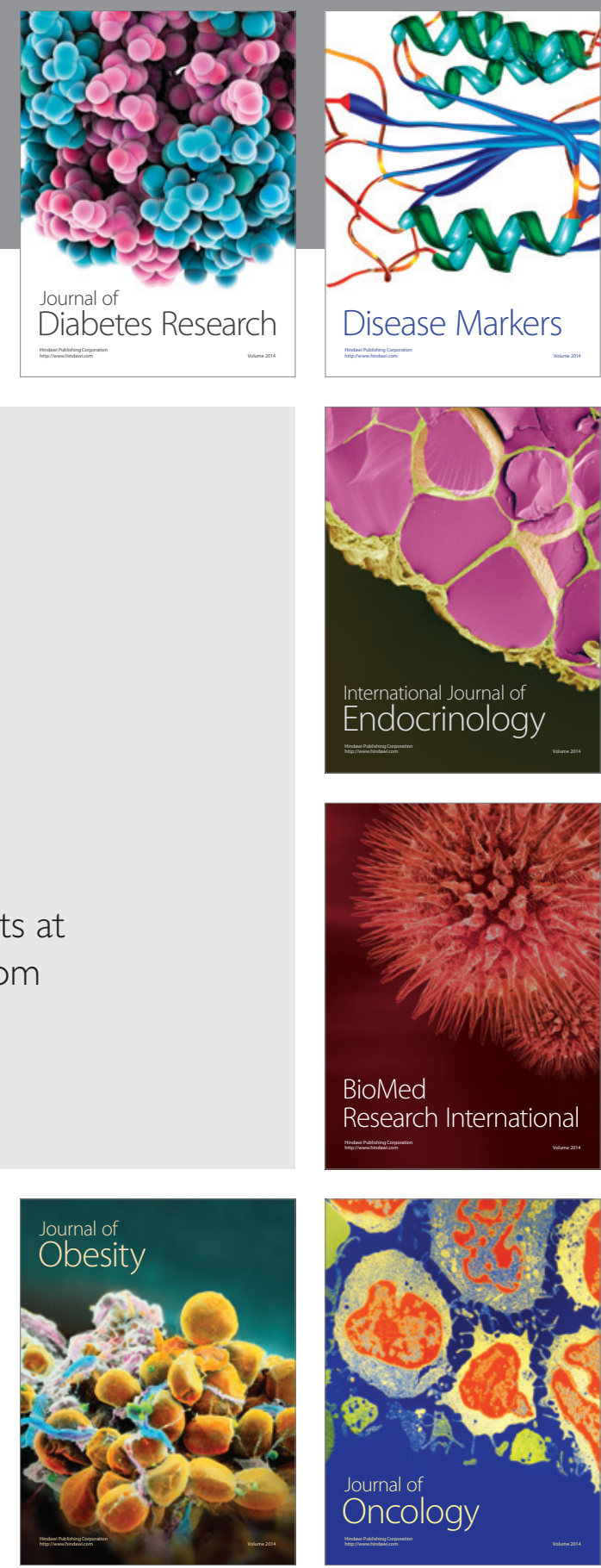

Disease Markers
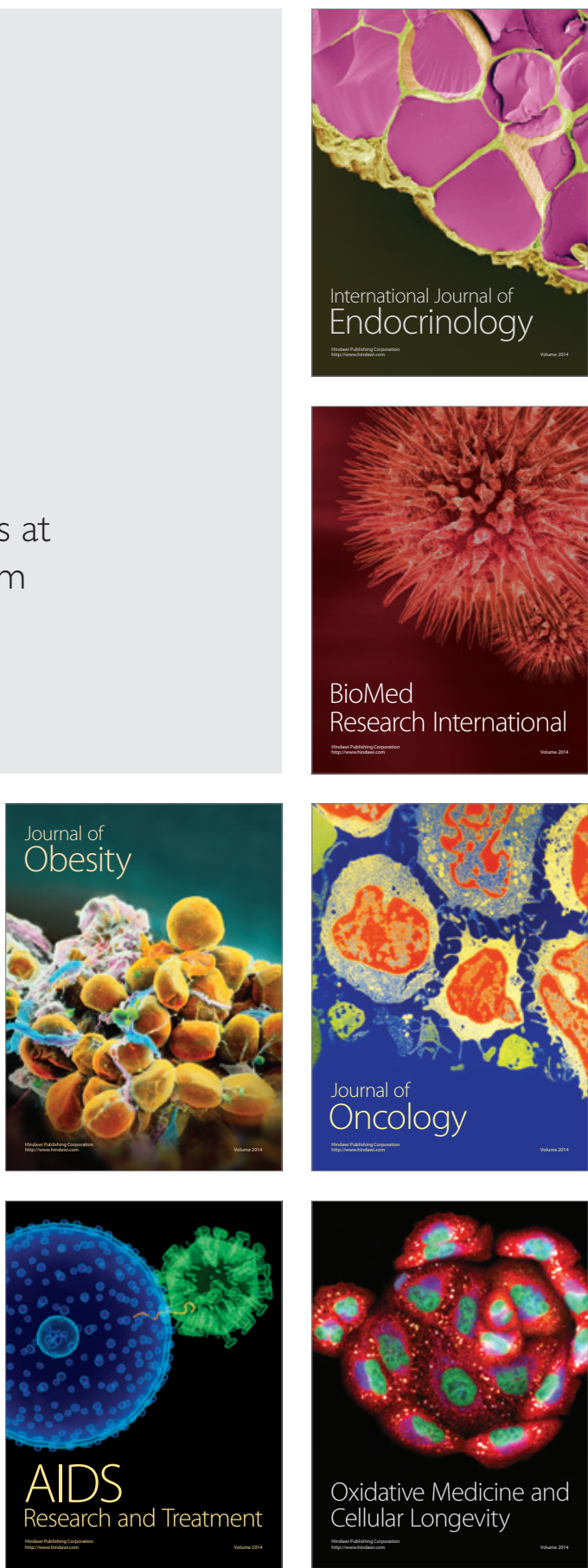